\title{
Promoting Collaborative Pedagogy in Classrooms: Challenges AND SOLUTIONS
}

\author{
Bunmi Isaiah Omodan ${ }^{1}$ \\ 1) Walter Sisulu University, South Africa \\ E-mail: bomodan@wsu.ac.za
}

\begin{abstract}
Collaborative pedagogy appears to be productive among students and thereby adopted in many classrooms to ensure that students are active participants in the knowledge production process. However, challenges exist among students, alongside their instructors, which hinders the active involvement of students in the collaborative knowledge production process. In the same vein, the study also examines the possible ways to navigate the challenges. The argument is located within social constructivism and conceptual analysis of collaborative pedagogy to explore the trajectories of collaborative classrooms in schools. In response to the challenges, the study proposed solutions that include promotion of unity in diversities among students, the introduction of cultural variations in classrooms, and instigation of student's readiness to interact. The study concludes that collaborative knowledge construction is worthy of being promoted with the recommendation that schools should ensure that students are taught to be united in the process of generating knowledge and that there must be concerted efforts to teach different cultures in the system with student motivation for natural interest.
\end{abstract}

Keywords: Collaborative Pedagogy; Cultural variation; Collaborative Knowledge Construction; Challenges and Solutions.

\section{INTRODUCTION}

Collaborative classrooms appear to be productive among students and thereby adopted in many universities to ensure that students are active participants in the knowledge production process. This revelation perhaps justified the argument of Zhou, et al. (2021) that a collaborative classroom creates an environment where the power of experience is magnified through group work, collaborative learning activities, dialogue and teaching as a conversation. This implies that two or more people work together mutually and having a common purpose while remaining individually responsible. For doing so, the product of their action is called collaborative classroom, which can occur between learners from different fields of study, between instructors and their students or even within student groups themselves, including peer-to-peer collaboration.

From the perspective of Robinson (2013), collaborative pedagogy focuses on three key elements: intellectual autonomy, social affiliation, and emotional engagement. Emotional engagement builds strong and positive relationships among learners. This idea is not only limited to learning but also extend to teaching. That is, there is also collaborative teaching and learning, which involves interaction between individuals or groups that are working towards a common goal, and involve both cognitive and social processes (Clarke \& Kinuthia, 2009). This involves a variety of techniques for actively involving students as colearners through small group work, such as an arrangement of teams prior to instruction; posting questions before instructional sessions so that all students may have an opportunity to clarify questions before the meeting; arranging seating arrangements to get students talking to one another (Harris \& Harvey, 2000; Caram \& Davis, 2005). In the same vein, Anfara Jr, \& Angelle (2007) view collaborative teaching as a way of leading, in which an instructor is concerned with the learning needs and interests of the individuals and their group.

As good as collaborative pedagogy appears to be widely implemented among educational institutions globally (Bozalek, et al., 2010; Craig, Poe \& Gonzalez Rojas, 2010; Altinyelken, 2012), there are still some challenges that hinder effective implementation among students. The collaborative teaching and learning process has its own set of challenges alongside some limitations that constitute a setback to its implementations in classrooms. A challenging environment for both instructors and students due to different factors such as power relations within the class, low quality interactions among peers and preferences that inhibit collaboration such as individualism value structure (Lomangino, Nicholson, \& Sulzby, 1999), imbalance of power between the students and their instructors (Willis, 
2014). Among the challenges also entails low quality interactions and preferences/values that inhibit collaboration such as individualism value structure (Le, Janssen, \& Wubbels, 2018) which is a practical contradiction that the ideal situation for achieving the objectives of learning is through active participation to work on real life problems along with higher levels of student engagement and motivation (Ismail et al., 2011). Limitless to these, a challenging environment for both instructors and students relating to power relations within the class, low-quality interactions among peers and preferences that inhibit collaboration such as individualism value structure also hinders students' effective classrooms activities.

Before the exploration of possible solutions to the challenges, it is pertinent to understand what could be responsible for such challenges in the process of implementing collaborative pedagogy. Among the reasons as indicated in the literature are; the hierarchical position of some persons over others within the group (Garandeau, Ahn \& Rodkin, 2011); students may think it is not ethical how one student dominating over another (Richmond, 1990); against the cultural norm of respecting other people's opinions as well as expressing their own. These challenges may also be caused by individualistic culture rather than collectivist generalisation, where students will prefer to work alone without communicating with other students. Even the students fear being embarrassed by sharing opinions in the class, which may result in low self-esteem and, further, lower academic performance.

The side effect of this is not limited to bad students' overall achievements as well as effective communication among students (Richmond, 1990). Research also confirms that cultural imposition and students with low self-esteem usually perform below average (Ross \& Broh, 2000; Radulović, Vesić, \& Malinić, 2020). However, in order to understand collaborative pedagogy, the place of Social Constructivism is imminent. Introduction: The introduction is containing the background with a problem solving, the urgency and rationalization of activities, bibliography, solution plan, the objective of the activity, and hypothesis development. Methodology: Research methodology explains about the approach, scope or object, operational definition in each variable/description of research focus, place, population and sample/informant, main source and tool, technique of data collection, and technique of data analysis. Results and Discussion: The findings is presented in full and related with the scope of the research determined before.

The findings can be completed with tables, graphs, and/or charts. The tables and pictures are given number and title. The result of data analysis is explained correctly in the article. The discussion part logically explains the findings, associated with the relevant sources. Conclusions: The conclusion contains the short summary of the findings and discussion. Conclusion is the findings in the research that has the answers for the research questions or the objective of the research. The research findings give suggestions or contributions to the application and/or the study development.

\section{Situating the study within Social Constructivism Framework}

I adopted social constructivism as a theoretical stand to understand the sociality that is peculiar in collaborative pedagogy. This framework is laced with social and societal pedestal in the process of knowledge construction (McMahon, 1997). That is, it processes constructing new knowledge using culture and societal context as the basis for the knowledge (Derry, 1999). This is not different from the analysis of Vygotsky (1986) that social constructivism is a method that accommodates discussion, interaction, communication and environmental tendencies as a fundamental content of knowledge.

This argument is not far from that is Kukla (2000) that knowledge and thinking is rooted in social construction among people or group of persons. "That is, their way of knowing is the premise upon the three constructs" (Omodan $\&$ Tsotetsi, 2020). This is also in line with the argument of Kim (2014:3), that the reality of human beings lies in the sociality of people around them. This was further exemplified that meaning is created through conversational interaction with environments (Amineh \& Asl, 2015). This encourages the coming together of different people to construct or create a new body of knowledge, which also enables the understanding of how individuals' worldviews are created by interactions with each other within their social context (Newman \& Holzman, 2003).

Deducing from classroom perspective, this framework involves identifying how students constructed meaning in specific situations. This forms an important part of the Social Constructionist approach because it helps to uncover hidden assumptions about human behaviour (Anderman, 2002), and get access to the hidden culture of students (Merriam \& Shaffir, 1998). I also argue that social constructionism gives access to ways in which different actors (people) and their activities are constructed by cognitive processes. This is my argument, which could stand as motivation and encourage students to look beyond what is obvious. Instead, the focus is on micro-scale level interactions where individual works together for a common purpose where meaning is created through social interaction. One could say that Social Constructivism's potential is in no way different from the assumptions of Collaborative pedagogy.

This theory is relevant to unpack the challenges of collaborative pedagogy among students because it is an approach that identified and expatiated how student's learning was influenced through group discussion and interaction. That is, how people orient themselves towards each other, identifying the basic values and assumptions that guide their actions offers a particular way of understanding interactions inside and outside schools (Abes, et al., 2007). Such identification also depicts that knowledge originates from social interaction and is also sustained by social interactions (Maor, 2003), with an opportunity to look at learning experiences from a new perspective. This theory also offers a window into the hidden culture of students meaning how individuals make sense of their world and 
interpret events (Lainema, 2009 From this argument, one could predict that social constructivism is an approach that could ameliorate the challenges of collaborative pedagogy. This is so because it will enable students to jettison every possible and thinkable issue that will affect their social interaction and unity in diversities towards knowledge production. The following session also discusses the conceptual framework for the study.

\section{Conceptual Framework: The relevant of Collaboration Pedagogy}

Collaborative Pedagogy improves engagement levels among students because they are able to work individually on their projects while still interacting with one another and discussing their progress with others (Bikowski, 2015). It encourages more students to take part in classroom activities and helps to shape a class discussion or project by bringing diverse perspectives as well as creating an open environment for all learners to be able to express themselves freely (Hutchinson et al., 2012). Collaboration in the classroom also allows for better reflection on practice and, in doing this, enables the teacher to develop a teaching style that encompasses future challenges within the learning environments while making use of existing knowledge among various collaborators (McKenna, Yalvac \& Light, 2009).

Likewise, it provides challenging engagement regardless of differences, which is why instructors should design and plan collaborative learning activities and classroom climates based on this value to ensure that all students have a sense of belongingness which is highly important in the pedagogical process (Colón García, 2017). From such engagement, mutual trust among teachers and learners are built on professional relationships that accommodate respect between and among individual members or groups. This could also motivate student involvement in class discussions since everyone is working together to clarify any points of confusion (Reichl, et al., 2014).

This exploration is a clear indication that collaboration activities are advantageous as compared to traditional methods. In such classroom method, learners gain valuable knowledge from their peers as well as instructors who act as role models, which is why I agree that with Reznitskaya (2009) that collaborative pedagogy promotes the acquisition of knowledge which enables learning by applying new information acquired from instructors or peers to undertake individual tasks. This is inconsonant with the argument of Le, Janssen \& Wubbels (2018) that classroom collaboration allows for the sharing of ideas as well as the interpretation and application of new information. Based on this, one could then argue that it is a platform for students to be able to apply their knowledge while interacting with others who are also actively seeking answers alongside them.

Kleine Staarman, Krol, Van der Meijden (2005) also argued alongside this to say that collaborative teaching and learning inspires peer-to-peer interactions between learners, which enables group members to work together towards developing knowledge constructively. Lastly, mutual interactions among students, according to Matsumoto et al. (2016) makes learning more enjoyable for everyone involved in learning activities, and it is advantageous for instructors since they can freely share ideas by interacting with individual or groups of learners depending on what is needed at that particular time. This is to confirm further that collaborative teaching and learning is not beneficial only to students, but also to the instructors. This is also confirmed by Gilles, Wilson \& Elias (2010) that two-way collaboration encourages instructors to improve their skills based on observations from collaborative learning activities, which in turn makes them better prepared to be able to answer questions, provide feedback and assistance as well as incorporate new ideas.

Having explored the potency of collaborative pedagogy in the classroom, alongside the theoretical underpinning of social constructivism, one could then raise the following question: What are the possible ways in which collaborative pedagogy could be implemented in classrooms towards student's success? Having raised the above research question, the following objective was formulated to guide the analysis: The study examines the possible solutions to the challenges of collaborative pedagogy in classrooms.

\section{Methodology}

In other to respond to the research question and objective, the study banked on the theoretical framework and the highlights from the conceptual framework. The assumption of social constructivism constitutes the ideas that were constructed as a solution to the challenges of collaborative pedagogy in the classrooms. This is in line with Merriam and Shaffir (1998) recommendation that the social constructionism approach encourages researchers "to look beyond the already existing knowledge in this field. The solutions that were highlighted are as follows; unity in diversities, the introduction of cultural variations in the classroom, and student's readiness to interact with colleagues.

These solutions were also discussed in reference to the conceptual framework of the study. The study further adopted literature analysis as a template to make sense of the proposed solution emanated from the theoretical and conceptual literature discussed above. According to McGee (2001 p. 1), the literature analysis is synonymous with arguments. That is, it is a process to "make a claim about the work and support your claim with evidence from the text as well as reasoning and analysis". This method of analysis is to persuade the readers how valid, reasonable, logical and reliable your argument is (Kajana, 2017). This method is appropriate for this study because it enables the researcher to freely use the relevant literature to validate the proposed solutions to the identified pedagogical challenges. 


\section{ANALYSIS OF THE SOLUTIONS}

As deduced from the above exploration, the following points were suggested as possible solutions to the challenges of collaborative pedagogy. They are unity in diversity, teaching of cultural variations in the classroom and student's readiness to interact with colleagues.

\section{Unity in diversities}

Based on the above exploration, the place of unity among students and even between the instructors and students can not be underestimated. This is because unity in diversity has been seen a the only means for achieving teamwork among students (Hiep, 2007). In an organisation comprising multiple identities, such as genders, race, intellectual and cultural differences (Robinson-Wood, 2016), the only ways in which success could be achieved are true unity and unanimous ways of doing things. Hence there is a need for unity among educators to ensure collaborative pedagogy. This is because student tends to perform better when they are united towards their goal in the classroom (Hiep, 2007). This is in consonance with the argument of Davis et al. (2012) that unity is a key contributor to student success when one of our goals in life is learning with other people. It ensures student success and makes it easier for information and knowledge to flow from teacher to student and vice versa (Rodeghero \& Freedman, 2009). In this argument, the diversities could be evidently viewed as a strength towards academic achievement.

Apart from the correlation between the unity in varsities and students achievement as indicated above, the place of attitudinal changes also appear as one of the products of unity among classroom participants. This is evidenced in the findings of Parker (2010) that oneness among students enables better attitudes towards academic work, which leads to improved performance of students, especially at the school level. It also promotes high levels of commitment on both parties, which then result in improved productivity, making the work done more effective than it would have been otherwise (Nir, 2002; Thompson, Kitchie \& Gagnon, 2011). In the same postulations, oneness among classroom participants also allows students to gain energy from each other, thus promoting the flow of ideas that helps to achieve success in the classroom (Larsen-Freeman, 2012).

From the above literature, one could then argue that when there is unity among the students, between students and instructors, taking cognizant of the diversities without discrimination boosts focus among class members (Omodan \& Ige, 2021), hence enabling them to put their focus on what is being taught and how it will be applied which positively impact student performance at school level. This further confirms that one of the ways collaborative pedagogy could be achieved is via unity, where students will be able to work together without discrimination and provide solutions to a complex problems. This also speaks to social constructivism in the sense that unity among students enables them to socially construct knowledge by working together to clarify any points of confusion (Hutchinson et al., 2012). According to Laal and Ghodsi (2012) argument, togetherness is a hallmark of collaborative teaching and learning.

\section{The teaching of cultural variations in the classroom}

In this study, cultural variation is the differences in the student cultural background. That, students, are from various cultural differences. This is peculiar in heterogeneous communities where there are multiple cultures and languages with different peculiarities (Salamone, 1997; Thomas \& Bendixen, 2000). Having confirmed that cultural differences have been a major challenge to classroom collaborative knowledge construction (So, Seah \& TohHeng, 2010), it is imminent to recommend introducing the teaching and awareness on students conflicting cultures. Understanding individual cultural diversity is important for teachers and students because it helps know your student's thoughts toward something and what should be said to make them understand better.

This argument is supported by Fredrickson (2015) that when students understand their backgrounds, it will enable them to know their weaknesses and respect their level of collaboration in classrooms. This is to confirm that introducing a curriculum that will teach students about their cultural diversities will go a long with promoting collaborative interest among students. The following literature also opens up on the correlation between cultural diversities and student's engagement.

The argument of Trice (2004) indicated that knowledge of diverse cultures assists students and influences their academic performance. This may not be unconnected to the fact that it will enable students from different backgrounds to come together and share valuable knowledge among themselves. Govea (2007) also identified cultural background in education as; collectivistic and individualistic with the recommendation that individualistic cultural is positive and should be understood in other for students to relate well with one another. The finding of Keumala, Samad, Samad \& Rachmawaty (2019) also confirm that learners understanding of their socio-cultural background contributes to their success and academic performance.

From the above literature, one could argue that the students' place of prior cultural knowledge will assist them to be accommodative with one another during their collaborative engagement. This is because people's culture tends to influences people attitudes and behaviours (Chandran \& Alammari, 2020). Therefore, when students are exposed to the cultural background of their colleagues, it will enable them to understand the based culture behind their actions. This is also in agreement with social constructivism that enables people (students) to orient themselves towards each other and indentify basic values and assumptions that guide each other's actions inside and outside schools 
(Cochran-Smith, 2000). Therefore, the introduction of this to students of any level will enhance collaborative pedagogy.

\section{Student's readiness to interact with colleagues}

Students' intention and willingness to get involved in social and classroom activities are also important and significant to collaborative pedagogy (Borokhovski et al., 2021). In this case, students' interest to interact or participate in collaborative engagement in the classroom is one of the motivating strategies teachers must ensure among students (Moore, 1989). This is to say that when students develop a natural interest in any process, they will be determined to make it a success. This is, it will enhance their inner interest, "including self-direction and self-motivation" (Borokhovski, et al., 2021 p. 313). This is in consonance with Young et al. (2003) finding that learners' performance is significant to students' understanding, skills, and readiness to learn new things. This is to say that students' performance in their schooling is associated with their positive attitude to their learning process, attitude to their peers, and even the instructors (Duke, 2002). When students show interest and are ready to engage with a positive attitude, then their pedagogical attitude is achievable, and they are likely to be committed to themselves in unity of purpose (Paswan and Young, 2002).

Based on this literature, one could then argue that the place of interest among students towards collaborative pedagogy is sacrosanct. By so doing, students must be encouraged and motivated to participate in classroom engagement. This solution could be ensured when there is a socially constructed knowledge production process. Such a process of sociality among students promotes their willingness to engage together, which leads to social relationships among them with the potential to improve their academic engagement (Alonso et al., 2015). This further confirms that it enhances social engagement, anchored instruction, collaborative social learning, and promotes social relationships among students (Bransford et al., 1990; Palloff \& Pratt, 2003; Alonso et al., 2015). The argument here is that students must be socially motivated to interact and engage in collaborative pedagogy.

\section{CONCLUSION AND RECOMMENDATIONS}

As good as collaborative pedagogy appears, literature and experiences demonstrated challenges that hinder its implementations in classrooms. Among the challenges are; cultural norm of respecting other people's opinions and the individualistic mentality. Hence, the literature also demonstrated that collaborative pedagogy is important to classroom productivity and facilitates collaboration among learners, instructors, and learner groups. Based on this, the study concluded that unity in diversities, cultural variations in the classroom, and student readiness to interact with colleagues are dimensions of collaborative pedagogy that could be implemented and achieved in classrooms. Based on this, the study recommends that:
- Schools and or curriculum planners should ensure that students are incorporated into the spirit of togetherness, unity and oneness among themselves. This is beneficial for the improvement of Collaboration activities because it compliments collaborative classrooms, thus improving their learning environment and allowing students to acquire knowledge that will enable them to apply what they have learned from class and enhance their performance in exams due to the development of Collaborative Learning Connections.

- Schools and curriculum planners should also ensure that knowledge of cultural variations that will enable students to understand their diverse cultural backgrounds should be taught and incorporated into the teaching system. This enables collaborations that help overcome individual weaknesses by encouraging interaction between students thus creating a sense of belongingness in class. It will also improve performance because students are not afraid to ask for help when they need it. Instructors and peers act as role models, which is why Collaborative Pedagogy encourages learners to express themselves while interacting with each other freely.

- And lastly, students must be motivated to naturally create interest and readiness to participate and engage in classroom and other social activities. This is fundamental to promote active participation among students, and it is also advantageous to both parties, instructors and students alike, to improve their skills, create a sense of belongingness among students and encourage individual empowerment, which helps overcome individual weaknesses.

\section{REFERENCES}

Abes, E. S., Jones, S. R., \& McEwen, M. K. (2007). Reconceptualising the model of multiple dimensions of identity: The role of meaningmaking capacity in the construction of multiple identities. Journal of college student development, 48(1), 1-22.

Alonso, F., Manrique, D., Martínez, L., \& Viñes, J. M. (2015). Study of the Influence of Social Relationships among Students on Knowledge Building Using a Moderately Constructivist Learning Model. Journal of Educational Computing Research, 51(4), 417-439. https://doi.org/10.2190/EC.51.4.c

Altinyelken, H. K. (2012). A converging pedagogy in the developing world? Insights from Uganda and Turkey. Global education policy and international development: New agendas. issues and policies, 201-221. https://hdl.handle.net/11245/1.390543

Amineh, R. J \& Asl, H. D. (2015). Review of Constructivism and Social Constructivism. Journal of Social Sciences, Literature and Languages. 1(1), 9-16. 
Anfara Jr, V. A., \& Angelle, P. S. (2007). Teachers as leaders: Collaborative leadership for learning communities. Middle School Journal, 38(3), 54-61.

Bikowski, D. (2015). The Pedagogy of Collaboration: teaching effectively within an evolving technology landscape. Innovation in English language teacher education, 223-231. https://www.britishcouncil.in/sites/default/files/tec1 4_papers_final_online.pdf\#page $=223$

Borokhovski, E., Tamim, R., Bernard, R. M., Abrami, P. C., \& Sokolovskaya, A. (2012). Are contextual and designed student-student interaction treatments equally effective in distance education? Distance Education, 33(3), 311-329. https://doi.org/10.1080/01587919.2012.723162

Bozalek, V., Carolissen, R., Leibowitz, B., Nicholls, L., Rohleder, P., \& Swartz, L. (2010). Engaging with difference in higher education through collaborative inter-institutional pedagogical practices. South African journal of higher education, 24(6), 10231037. https://hdl.handle.net/10520/EJC37652

Bransford, J. D., Sherwood, R. D., Hasselbring, T. S., Kinzer, C. K., Williams, S. M. (1990). Anchored instruction: why we need it and how technology can help. In D. Nix \& R. Sprio (Eds.), Cognition, education and multimedia. Hillsdale, NJ: Erlbaum Associates.

Caram, C. A., \& Davis, P. B. (2005). Inviting student engagement with questioning. Kappa Delta Pi Record, 42(1), 19-23.

Chandran, D., \& Alammari, A. M. (2020). Influence of Culture on Knowledge Sharing Attitude among Academic Staff in eLearning Virtual Communities in Saudi Arabia. Information Systems Frontiers, 110.

Clarke, P. A. J., \& Kinuthia, W. (2009). A Collaborative Teaching Approach: Views of a Cohort of Preservice Teachers in Mathematics and Technology Courses. International Journal of Teaching and Learning in Higher Education, 21(1), 1-12. https://files.eric.ed.gov/fulltext/EJ896237.pdf

Colón García, A. (2017). Building a sense of belonging through pedagogical partnership. Teaching and Learning Together in Higher Education, 1(22), 1-6

Craig, J., Poe, M., \& Gonzalez Rojas, M. F. (2010). Professional communication education in a global context: A collaboration between the Massachusetts Institute of Technology, Instituto Tecnológico y de Estudios Superiores de Monterrey, Mexico, and Universidad de Quintana Roo, Mexico. Journal of Business and Technical Communication, 24(3), 267-295.

https://doi.org/10.1177\%2F1050651910363269

Derry, S. J. (1999). A fish called peer learning: Searching for common themes. Cognitive perspectives on peer learning, 9(1), 197-211.

Duke, C. R. (2002). Learning outcomes: comparing student perceptions of skill level and importance. Journal of Marketing Education, 24(3), 203-17
Fredrickson, J. (2015). Online learning and student engagement: Assessing the impact of a collaborative writing requirement. Academy of Educational Leadership Journal, 19(3), 127.

Garandeau, C. F., Ahn, H. J., \& Rodkin, P. C. (2011). The social status of aggressive students across contexts: The role of classroom status hierarchy, academic achievement, and grade. Developmental psychology, 47(6), 1699.

Gardner, M., \& Elliott, J. (2014). The Immersive Education Laboratory: understanding affordances, structuring experiences, and creating constructivist, collaborative processes, in mixed-reality smart environments. EAI Endorsed Transactions on Future Intelligent Educational Environments, 14(1), 1-13. http://repository.essex.ac.uk/id/eprint/10615

Gilles, C., Wilson, J., \& Elias, M. (2010). Sustaining teachers' growth and renewal through action research, induction programs, and collaboration. Teacher Education Quarterly, 37(1), 91-108. https://eric.ed.gov/?id=EJ872651

Harris, C., \& Harvey, A. N. (2000). Team teaching in adult higher education classrooms: Toward collaborative knowledge construction. New Directions for Adult and Continuing Education, 87, 25-32.

Hiep, P. H. (2007). Communicative language teaching: Unity within diversity. ELT journal, 61(3), 193-201.

Ismail, M., Diah, N. M., Ahmad, S., \& Rahman, A. A. (2011). Engaging learners to learn tajweed through active participation in a multimedia application (TaLA). In 3rd International Conference on Advances in Computing, Control and Telecommunication Technologies (pp. 88-91).

Kajana, S. M. (2017). LITERATURE ANALYSIS FOR ORDINARY LEVEL. Dodoma-Tanzania: Sam Elly Press.

Keumala, M., Samad, N. M. A., Samad, I. A., \& Rachmawaty, N. (2019). The Influence of Socio Cultural and Educational Background on EFL Learners' Motivation. Indonesian TESOL Journal, 1(1), 67-77. https://doi.org/10.24256/itj.v1i1.556

Kim, B. (2001). Social constructivism. Emerging perspectives on learning, teaching, and technology, 1(1), 16.

Kleine Staarman, J, Krol, K, Van der Meijden, H (2005) Peer interaction in three collaborative learning environments. Journal of Classroom Interaction 40(1), 29-39.

Kukla, A. (2000). Social Constructivism and the Philosophy of Science. New York: Routledge.

Laal, M., \& Ghodsi, S. M. (2012). Benefits of collaborative learning. Procedia-social and behavioral sciences, 31, 486-490.

Lainema, T. (2009). Perspective making: Constructivism as a meaning-making structure for simulation gaming. Simulation \& Gaming, 40(1), 48-67.

Larsen-Freeman, D. (2012). From Unity to Diversity: Twenty-Five Years of Language-Teaching 
Methodology. In English teaching forum (Vol. 50, No. 2, pp. 28-38). US Department of State. Bureau of Educational and Cultural Affairs, Office of English Language Programs, SA-5, 2200 C Street NW 4th Floor, Washington, DC 20037.

Le, H., Janssen, J., \& Wubbels, T. (2018). Collaborative learning practices: teacher and student perceived obstacles to effective student collaboration. Cambridge Journal of Education, 48(1), 103-122. https://doi.org/10.1080/0305764X.2016.1259389

Le, H., Janssen, J., \& Wubbels, T. (2018). Collaborative learning practices: teacher and student perceived obstacles to effective student collaboration. Cambridge Journal of Education, 48(1), 103-122. https://doi.org/10.1080/0305764X.2016.1259389

Lomangino, A. G., Nicholson, J., \& Sulzby, E. (1999). The influence of power relations and social goals on children's collaborative interactions while composing on computer. Early Childhood Research Quarterly, 14(2), 197-228.

Maor, D. (2003). The teacher's role in developing interaction and reflection in an online learning community. Educational Media International, 40(1-2), 127-138.

McGee, S. J. (2001). Analysing literature. Salina, Kansas: Longman. Retrieved from http://wps. ablongman. com/wps/media/objects/327/335558/AnalyzingLit. pdf.

McKenna, A. F., Yalvac, B., \& Light, G. J. (2009). The role of collaborative reflection on shaping engineering faculty teaching approaches. Journal of Engineering Education, 98(1), 17-26.

McMahon, M. (1997, December). Social constructivism and the World Wide Web-A paradigm for learning. In ASCILITE conference. Perth, Australia (Vol. 327).

Moore, M. G. (1989). Three types of interaction. American Journal of Distance Education,3(2), 1-7. https://doi.org/10.1080/08923648909526659

Newman, F., \& Holzman, L. (2013). Lev Vygotsky (classic edition): Revolutionary scientist. Psychology Press. https://doi.org/10.4324/9780203758076

Nir, A. E. (2002). School-based management and its effect on teacher commitment. International Journal of leadership in Education, 5(4), 323-341.

Omodan, B. I., \& Tsotetsi, C. T. (2020). Decolonisation of knowledge-construction in university classrooms: the place of social constructivism. African Journal of Gender, Society and Development (formerly Journal of Gender, Information and Development in Africa 9(2), 183-204. https://doi.org/10.31920/2634-3622/2020/9n2a10

Palloff, R., \& Pratt, K. (2003). The virtual student: A profile and guide to working with online learners. San Francisco, CA: Jossey-Bass.

Parker, W. (2010). Listening to strangers: Classroom discussion in democratic education. Teachers College Record, 112(11), 2815-2832.

Paswan, K. A., Young, J. A, (2002). Student evaluation of instructor: a nomological investigation using structural equation modeling. Journal of Marketing Education, 24(3), 193-202.

Radulović, M., Vesić, D., \& Malinić, D. (2020). Cultural capital and students' achievement: The mediating role of self-efficacy. Sociologija, 62(2), 255-268.

Reichl, C., Wach, F.-S., Spinath, F. M., Brünken, R., \& Karbach, J. (2014). Burnout risk among first-year teacher students: The roles of personality and motivation. Journal of Vocational Behavior, 85(1), 85-92. https://doi.org/10.1016/j.jvb.2014.05.002

Reznitskaya, A., Kuo, L. J., Clark, A. M., Miller, B., Jadallah, M., Anderson, R. C., \& Nguyen-Jahiel, K. (2009). Collaborative reasoning: A dialogic approach to group discussions. Cambridge journal of education, 39(1), 29-48.

Richmond, V. P. (1990). Communication in the classroom: Power and motivation. Communication Education, 39(3), 181-195. https://doi.org/10.1080/03634529009378801

Robinson, K. (2013). The interrelationship of emotion and cognition when students undertake collaborative group work online: An interdisciplinary approach. Computers \& Education, 62, 298-307. http://dx.doi.org/10.1016/j.compedu.2012.11.003

Robinson-Wood, T. (2016). The convergence of race, ethnicity, and gender: Multiple identities in counseling. Sage Publications.

Ross, C. E., \& Broh, B. A. (2000). The roles of self-esteem and the sense of personal control in the academic achievement process. Sociology of education, 270284

Salamone, F. A. (1997). Ethnicity and Nigeria since the end of the civil war. Dialectical anthropology, 22(3/4), 303-333.

So, H. J., Seah, L. H., \& Toh-Heng, H. L. (2010). Designing collaborative knowledge building environments accessible to all learners: Impacts and design challenges. Computers \& Education, 54(2), 479490

Thomas, A., \& Bendixen, M. (2000). The management implications of ethnicity in South Africa. Journal of International Business Studies, 31(3), 507-519.

Thompson, R., Kitchie, L., \& Gagnon, R. (2011). Constructing an online professional learning network for school unity and student achievement. Corwin Press.

Vygotsky, L. 1986. Thought and language. Cambridge, MA.: MIT Press

Willis, J. (2014). Making space to learn: Leading collaborative classroom design. Journal of Educational Leadership, Policy and Practice, 29(1), 3-16.

Young, M. R., Klemz, B. R., Murphy, J. W. (2003). Enhancing learning outcomes: the effectsof instructional technology, learning styles, instructional methods, andstudent behavior. Journal of Marketing Education, 25(2),130-42. 
Zhou, Q., Suraworachet, W., Pozdniakov, S., MartinezMaldonado, R., Bartindale, T., Chen, P., ... \& Cukurova, M. (2021). Investigating students' experiences with collaboration analytics for remote group meetings. In International Conference on Artificial Intelligence in Education (pp. 472-485). Springer, Cham. 